Pawet FUC

Filip MARKIEWICZ

Michat DOBRZYŃSKI

\title{
Problems of exhaust emissions testing from machines and mobile devices in real operating conditions
}

The article presents selected problems concerning tests of toxic exhaust emissions from engines of vehicles, mobile devices, engines used in gardening and construction works. For this group of engines, this type of testing is carried out primarily in laboratory conditions, however, variable load conditions during actual operation justify efforts to determine the level of emissions in real operating conditions. Research in real operating conditions for different engine categories becomes increasingly more standard, in this aspect, it is necessary to verify the state of knowledge and methodology in the aspect of testing engines of machines and mobile devices. The research performed by the authors was the first of this type using PEMS equipment, hence some conclusions and observations can be made from the obtained results. At present, the type approval procedures for the engine group in question do not account for emissions tests in real operating conditions, while also missing any description of a standardized research methodology. In addition, the engine group in question is not really suitable for testing in real conditions. An introduction to research aimed at developing an exhaust emission test methodology in real operating conditions of mobile device engines was included in the article.

Key words: emission, combustion engines, PEMS

\section{Introduction}

The continuous development of the construction, agricultural and gardening industries proportionally influences the growth of hand operated devices that facilitate and significantly accelerate both the simplest and the most complicated activities. In addition, there is more and more automation, which forces the development of industries, dealing in the production of handheld devices and all kinds of machinery and equipment, which also belong to the segment of non-road mobile machinery. In practice, their availability on the market and easy operation means that we have a wide range of devices equipped with small engines with a net power of not more than $19 \mathrm{~kW}$. The operation of engines used for vehicle drives and devices with various purposes usually takes place in states different from the optimal ones. Variable ambient conditions, high frequency of starting cycles and operation in a wide range of rotational speeds, as well as a wide range of engine loads, make it difficult to achieve a low level of harmful emissions. From the point of view of the emission of toxic compounds, the most unfavorable and unexpected is the operation of the engine in transient states, including in the period of cold start-up and during heating. An engine that has not reached the rated operating conditions, particularly for the temperature parameter, usually has a high concentration of carbon monoxide (CO) emissions as well as hydrocarbons (HC) at a slightly reduced level of nitrogen oxides $\left(\mathrm{NO}_{\mathrm{x}}\right)$ emissions. Additionally, for the group of $\mathrm{CI}$ engines, an increased issue of particulate matter (PM) is also a very important problem.

The current state of legal regulations in the field of homologation and toxicity tests does not impose on manufacturers and users of manual devices using small engines the obligation to subject the operated machines to emission control tests. This is a legal gap, which includes a large group of single-cylinder engines with spark ignition and compression ignition, used to drive small devices. Litera- ture analysis shows that no exhaust emission standards can negatively affect the pollution of the natural environment, because the increase of toxic exhaust emissions in such engines occurs as a result of their excessive use [4, 5]. In this type of devices, it is the high rotational speeds of the crankshaft of the engine and the power generated in this range during the work cycle, which guarantees a large expenditure of work and short cycle times, ensure perfect engine preparation for operation even in difficult conditions causing large changes in amplitude load. Hand operated equipment engines perform their tasks to a significant extent, with the participation of a working time representative of the external characteristics. Such nature of their work is burdened with a high probability of occurrence of emission changes caused by improper engine operation. This happens due to the wear of its elements and changing the settings of certain parameters. One of the other problems that occurs in spark ignition engines is the need to use an oil fuel mixture in the combustion process. Too high oil content in the fuel volume causes excessive emission of toxic compounds.

Hand machines are most often equipped with a SI two stroke engine. The simpler construction and the more power to weight ratio of the engine compared to the four stroke engine results in fitting of two stroke engines in these devices. In terms of design, they differ from engines mounted in vehicles. These differences result from the specific working conditions of the machines in which they are mounted [1]:

- working at 35-45' lateral inclination;

- work at longitudinal tilt 40-45', in special applications 60';

- working conditions: atmospheric pressure, temperature, humidity;

- high variability of external loads;

- adaptation to cooperation with a hydrokinetic transmission or a clutch - converter;

- special designs of air filters to work with high dust; 
- installation of silencers in the exhaust system with a spark absorber;

- relatively simple service, especially easy access to consumables (filters, drain plugs for operating fluids)

Despite so many ways to reduce toxic exhaust emissions, it is difficult to reduce them because of the need to maintain a relatively low weight of the device. The need to manually operate a device equipped with an internal combustion engine together with it's equipment adapted to perform a specific activity limits the installation of exhaust gas cleaning systems. The presented situation motivates to take steps enabling state-technical assessment of combustion engines in devices with such a wide application, whose population is growing at a significant pace, it seems inevitable that procedures enabling control of emissivity for this group of non-road machines and devices will be unavoidable.

\section{Methodology of research}

The ecological aspects of internal combustion engines due to the emission of pollutants are strongly determined depending on the conditions of the work performed. It is crucial to correctly interpret problems related to the formalization of the suitability of the conditions of use and the development of an engine test method to assess them. The methods by which this type of information can be obtained are constantly sought for. Standard acquisition of time density characteristics for working engines is carried out during measurements on stationary engine test benches [6]. However, these tests allow only the information to be obtained at fixed work points, which significantly limits the acquisition of a lot of information. Therefore, the determination of representative work points for the category of drive units intended for the operation of non-road mobile machines is in many cases impossible to achieve. Proposing a universal procedure that allows the measurement of a reliable emission level is associated only with the use of a test method allowing the registration of parameters under conditions of actual use [2]. Previously, measurements of this type were limited mainly by the research facilities allowing the work to be performed only in laboratory conditions. The emergence of a method based on the possibility of using PEMS (Portable Emissions Measurement System) equipment, gives a new possibility of connecting for research purposes analyzers to small mobile devices equipped with internal combustion engines and adapting it to perform measurements in difficult operating conditions (Fig. 1) [3].

One of the devices enabling the implementation of measurements in real-life conditions is the Axion RS mobile analyzer (Fig. 2) from the company GLOBAL MRV belonging to the PEMS type analyzer group. It is a unique combination of measurement and registration of the following parameters:

- concentrations of $\mathrm{CO}$ and $\mathrm{CO}_{2}, \mathrm{NO}_{\mathrm{x}}=\mathrm{NO}+\mathrm{NO}_{2}, \mathrm{THC}$ and $\mathrm{O}_{2}$;

- determining the mass flow of exhaust gases;

- working conditions - atmospheric pressure, temperature, humidity;
- position and speed of the tested object - GPS (Global Positioning System);

- engine crankshaft speed.

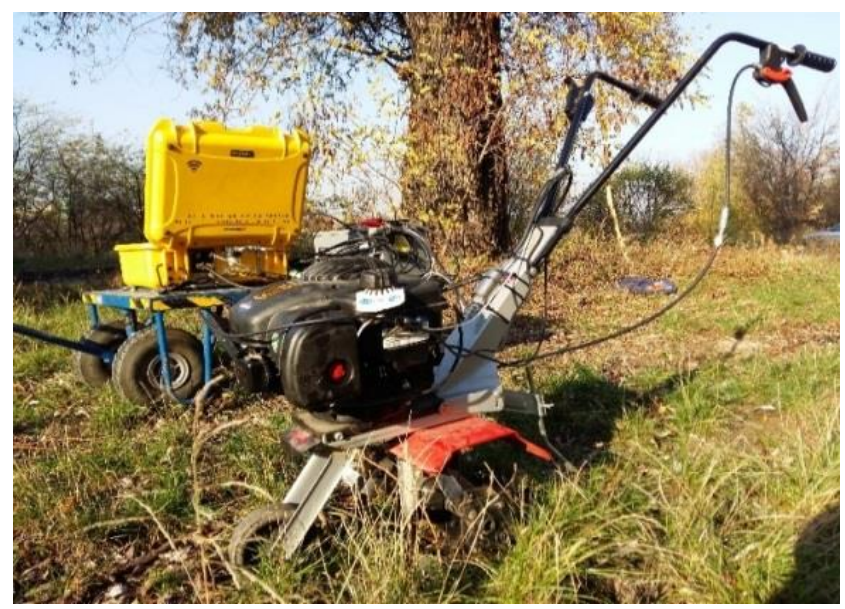

Fig. 1. Measuring system in real operating conditions

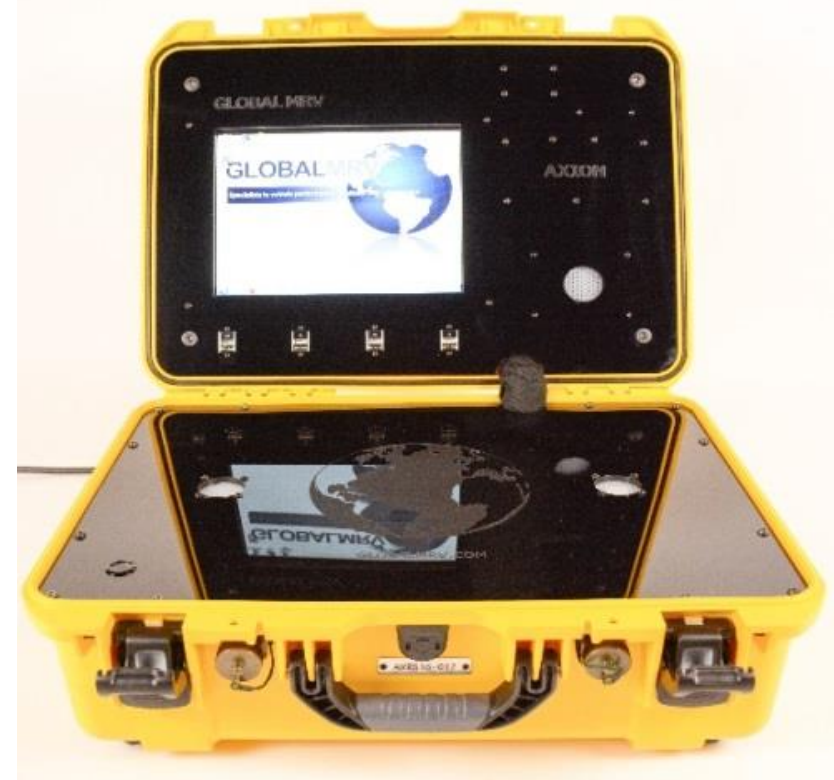

Fig. 2. Mobile exhaust gas analyzer Axion RS [8]

Table 1. Technical parameters from the analyzer device [8]

\begin{tabular}{|c|c|c|c|}
\hline Gas & $\begin{array}{c}\text { Measurment } \\
\text { range }\end{array}$ & Accurancy & Resolution \\
\hline $\begin{array}{c}\mathrm{HC} \\
\text { Propane }\end{array}$ & $0-4000[\mathrm{ppm}]$ & $\begin{array}{c} \pm 8[\mathrm{ppm}] \mathrm{abs} . \\
\text { or } \pm 3[\%]\end{array}$ & $1[\mathrm{ppm}]$ \\
\hline $\mathrm{CO}$ & $0.00-10.00[\%]$ & $\begin{array}{c} \pm 0.02[\%] \mathrm{abs} . \\
\text { or } \pm 3.00[\%]\end{array}$ & $\begin{array}{c}0.01 \mathrm{vol} . \\
{[\%]}\end{array}$ \\
\hline $\mathrm{CO}_{2}$ & $0.00-16.00[\%]$ & $\begin{array}{c} \pm 0.30[\%] \mathrm{abs} . \\
\text { or } \pm 3.00[\%]\end{array}$ & $\begin{array}{c}0.01 \mathrm{vol} . \\
{[\%]}\end{array}$ \\
\hline $\mathrm{NO}$ & $0-4000[\mathrm{ppm}]$ & $\begin{array}{c} \pm 25.00[\mathrm{ppm}] \mathrm{abs} . \\
\text { or } \pm 4.00[\%]\end{array}$ & $1[\mathrm{ppm}]$ \\
\hline $\mathrm{O}_{2}$ & $0.00-25.00[\%]$ & $\begin{array}{c} \pm 0.10[\%] \mathrm{abs} . \\
\text { or } \pm 3.00[\%]\end{array}$ & $\begin{array}{c}0.01 \mathrm{vol} . \\
{[\%]}\end{array}$ \\
\hline
\end{tabular}

An important problem of modern equipment is their limited scope of measurement resolution. The level of detection of concentrations of gaseous exhaust components makes it impossible to study in a wide spectrum, which in 
the case of engines not equipped with any exhaust gas cleaning systems as well as those operating in the work circuit, characteristic for two-stroke units, enforces the use of the most modern solutions that give the possibility of diluting the exhaust sample. In order to extend the measurement possibilities in conditions of very high concentrations of gaseous components it is necessary to use an additional system operating as an exhaust diluent (Fig. 3), which in a given dimensional range and dilution tunnel allows for preparation of a sample for analysis in a measuring track. Such equipment allows the use not only in stationary conditions, but also in dynamic conditions, e.g. during engine start up, as well as in transient conditions between dynamic load change.

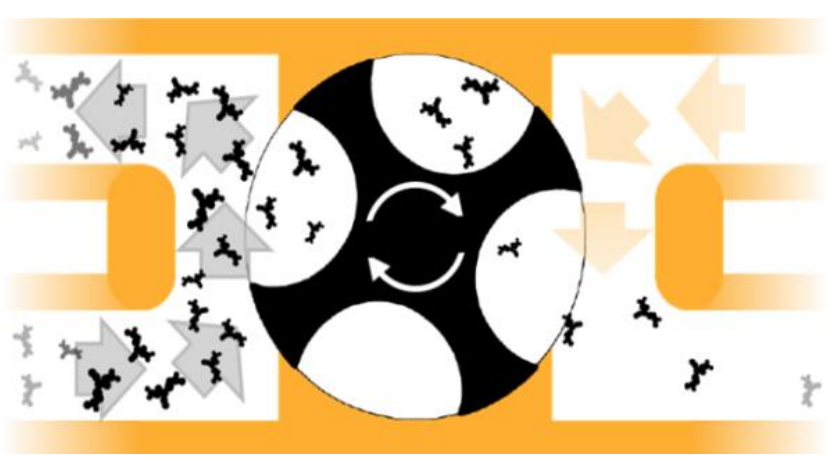

Fig. 3. View of the operation of the sample diluent tunnel [9]

One of the solutions is a device available from the TSI manufacturer Rotating thermal disk (Fig. 4). Particularly suitable for sampling, diluting and conditioning of exhaust particles from diesel and sparking engines. In addition, it is equipped with a thermal conditioner that can be heated to $400^{\circ} \mathrm{C}$, to eliminate nano drops that may have formed during the dilution process. It also has the ability to function functions in the source (exhaust pipe, tunnel or stack) and thermally conditions the particles to keep them accurate for measurement.

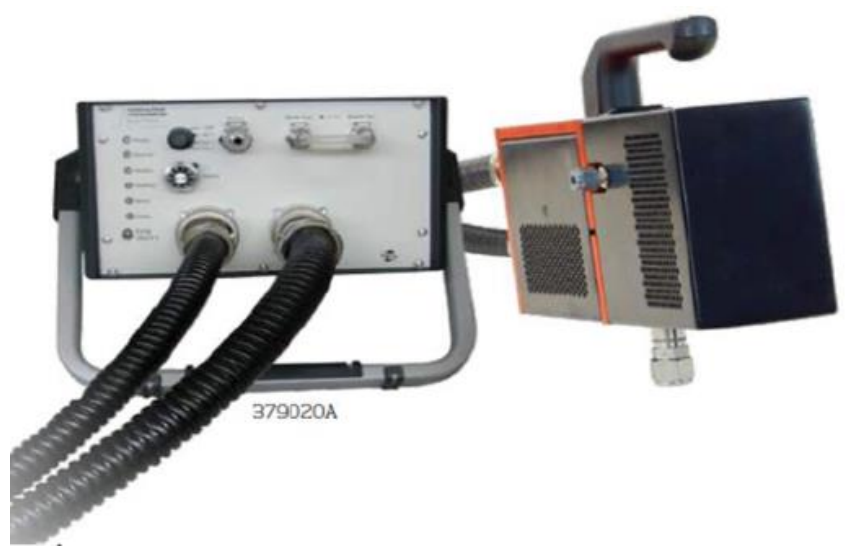

Fig. 4. TSI gas diluter [9]

\section{Measurements under real operating conditions}

In field trials, the preparation of a test device is also a very important element. The key issue is to adapt the test facility in order to be able to mount a group of sensors enabling the determination of the mass value of exhaust gas flow rates. This connection requires maintaining tight-ness during testing so as to eliminate dilution by atmospheric air.
It is required that the pressure sensor is mounted in a vertical position in order to avoid disturbances in the measurement due to the possible occurrence of condensation of the fuel-air mixture in the intake system. The length of the connection between the flow meter and the end of the engine exhaust system must be relatively short to prevent unnecessary pulsation. The next stage is the construction of a connection enabling the registration of the rotational speed of the crankshaft during the operation of the device. Exemplary methods of application of the apparatus for performing tests under real operating conditions are shown below (Fig. 5).

Before carrying out measurements, the issue of powering the measuring devices should be solved. Under test conditions of tested objects the apparatus needs energy to operate, therefore it is necessary to use an available source from the installation of the device under test. If the tested object does not have its own power supply, or does not generate a minimum value of $12 \mathrm{~V}$, then an additional power generator is needed. In the first stage, the analyzer should be conditioned, the leak test of this connection should be carried out and during the measurements it should be monitored if its tightness is maintained. This has a significant impact on the elimination of possible potential measurement errors. Before starting the work of the object, the registration of defined parameters starts. In order to get a full description, which will enable a complete analysis of the share of working time at individual points, a test should be carried out according to a pre-proposed schedule:

- starting up the device and conditioning during the normalized engine crankshaft speed for idling;

- lower crankshaft speed for generating loads below $<50 \%$ of maximum power;

- dynamic changes in the full speed range and load values characteristic of the actual operation conditions;

- higher value of crankshaft speed for the generated load below $>50 \%$ of maximum power for a given structure;

- minimum engine crankshaft speed at which maximum torque is possible;

- in the case when the device is self-propelled, registration of parameters during the travel of the road to the place of performed tasks, as well as after their completion.
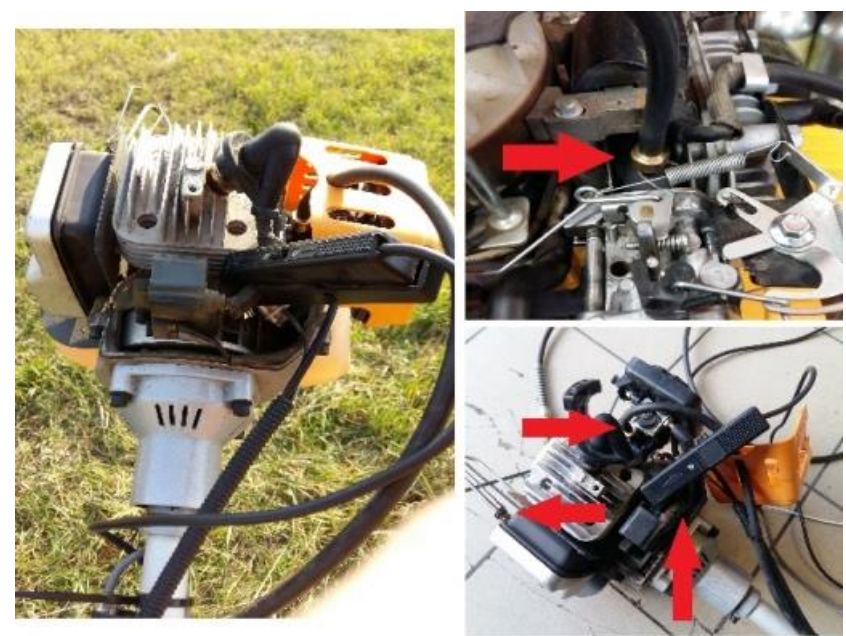

Fig. 5. Measuring elements during installation in a mobile devices 
The preliminary analysis on selected objects show high variability of ecological parameters. Through the curves obtained, we can analyze the impact of various factors on emission changes relative to the change in speed and load resulting from the specifics of the device's operation. The following characteristic (Fig. 6) shows how important the test conditions are for the selected example for a research object. Visible changes in $\mathrm{HC}$ emissions show how reasonable it is to strive for tests under real operating conditions. They allow showing real values during operation. Differences resulting from work between static conditions and test dynamic conditions reach a discrepancy at the level of growth reaching $25 \%$. The application of the presented research methodology also gives new possibilities for nonroad mobile devices.

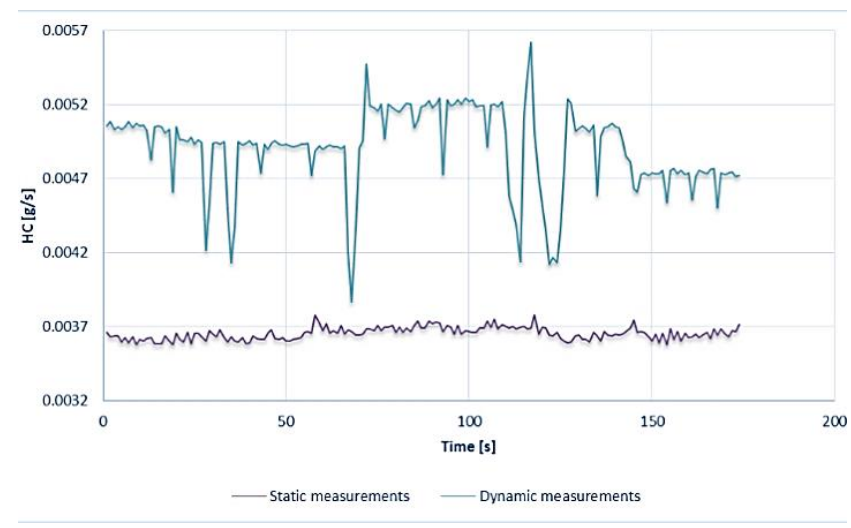

Fig. 6. The dependence of $\mathrm{HC}[\mathrm{g} / \mathrm{s}]$ emission under test conditions

It also provides information about real fuel consumption using the carbon balance method according to the following formula:

$$
\mathrm{FC}_{\mathrm{W}}=\frac{0.1155}{\rho_{\text {fuel }}}\left[(0.866 \cdot \mathrm{HC})+(0.429 \cdot \mathrm{CO})+\left(0.273 \cdot \mathrm{CO}_{2}\right)\right]
$$

where: $\mathrm{FC}$ - fuel consumption $\left[\mathrm{dm}^{3} / 100 \mathrm{~km}\right] ; \mathrm{HC}, \mathrm{CO}, \mathrm{CO}_{2}$ - emission of ingredients harmful $[\mathrm{g} / \mathrm{km}] ; \rho_{\text {fuel }}-$ fuel density at temperature $15^{\circ} \mathrm{C}\left[\mathrm{g} / \mathrm{cm}^{3}\right]$.
Due to significant construction constraints (the impossibility of assembling of measuring elements) up to this time the indications were usually limited to organoleptic control.

\section{Summary}

The problem of non-road mobile machines presented in this article is highly significant. The currently produced drive units for this category of equipment are not subject to legal regulations and emission standards such as those required for approval tests. It causes their significant deviations from any levels for emission limits in relation to commonly used drive units mounted even in vehicles. The undertaken works indicate, that the load and speed of the engine have a significant impact on the exhaust emissions of the tested engines. The operation of the engines in small devices is characterized by changes in engine speed and engine load that are likely to cause relatively high exhaust emissions. Initial analyzes confirm that the direction of the undertaken activities will enable a more precise definition of the problem that is the negative environmental impact of the operated equipment. The creation of a universal methodology in research during real working conditions can be successfully used in the development of small engines installed in devices dedicated to manual work. It is necessary however, to continue development work on improving not only the measuring equipment intended for the engine of these devices, engines themselves, but also emission assessment methods. Measurements carried out on small motors under static conditions differ from measurements made under the conditions of the final use. An important issue is the adaptation of PEMS measuring equipment. Most of these devices have exhaust system components and a mass flow range beyond the range corresponding to the small engine category. An additional problem is the need for a compact design of measuring equipment. Carefully analyzing current trends in engine exhaust emissions, seems it is entirely reasonable to undertake emission tests related to small engines operating under real operating conditions. In the future, such tests should be included in the approval procedure.

\section{Nomenclature}

CI compression ignition

GPS global positioning system

NDIR non-dispersive infrared

PEMS portable emission measurement system
PM particulate matter

RDE real driving emissions

SI spark ignition

$\mathrm{T}$ temperature

\section{Bibliography}

[1] BRACH I., TYRO, G. Maszyny ciągnikowe do robót ziemnych. WNT. Warszawa 1986.

[2] RYMANIAK, Ł. Comparison of the combustion engine operating parameters and the ecological indicators of an urban bus in dynamic type approval tests and in actual operating conditions. MATEC Web of Conferences. 2017, 118, EDP Sciences.

[3] MERKISZ, J., KOZAK, M., NIJAK, D. et al. The analysis of the emission level from heavy-duty truck in a city traffic. Combustion Engines. 2012, 151(3), 80-88.

[4] MERKISZ, J, PIELECHA, J., RADZIMIRSKI, S. New trends in emission control in the European Union. Book Se- ries: Springer Tracts on Transportation and Traffic, 2014, 4, 1-170.

[5] MERKISZ, J, PIELECHA J., GIS, W. Comparison of vehicle emission factors in NEDC cycle and road test. 9th AsiaPacific International Symposium on Combustion and Energy Utilization Location, Proceedings of the ninth Asia-Pacific International Symposium on Combustion and Energy Utilization. 2008, 477-482.

[6] MERKISZ, J., PIELECHA, J., PIELECHA, I., SZUKALSKI, M. Emisja dwutlenku węgla przez silniki pojazdów specjalnych w rzeczywistych warunkach ruchu. Transport Samochodowy, 2010. 
[7] BAJERLEIN, M., RYMANIAK, L., SWIATEK, P. et al. Modification of a hybrid city bus powertrain in the aspect of lower fuel consumption and exhaust emissions. Applied Me-

Prof. Piotr Lijewski, DSc., DEng. - Faculty of Transport Engineering, Poznan University of Technology.

e-mail: Piotr.Lijewski@put.poznan.pl

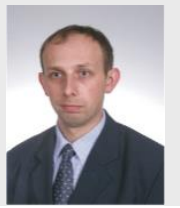

Filip Markiewicz, MEng. - Faculty of Transport Engineering, Poznan University of Technology.

e-mail: Filip.Markiewicz@put.poznan.pl chanics and Materials. Trans Tech Publications. 2014. 108113.

[8] Global MRV Incorporated, Producer Materials 2019.

[9] TSI Incorporated, Producer Materials 2018.

Prof. Paweł Fuć, DSc., DEng. - Faculty of Transport Engineering, Poznan University of Technology.

e-mail:Pawel.Fuc@put.poznan.pl

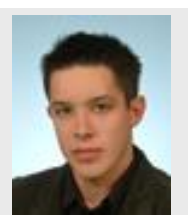

Michał Dobrzyński, DEng. - Faculty of Transport Engineering, Poznan University of Technology.

e-mail: Michal.Dobrzynski@put.poznan.pl 